\title{
Gestão em Organizações do Terceiro Setor Associação Pestalozzi de Porto Velho
}

\author{
Oleides Francisca de Oliveira \\ Doutora em Desenvolvimento Regional pela Universidade \\ de Santa Cruz do Sul - Unisc/RS. Docente do Centro de \\ Ciências Jurídicas e Sociais Aplicadas no curso de Ciên- \\ cias Econômicas, na Universidade Federal do Acre - Ufac. \\ oleides.ufac@gmail.com
}

\section{Nazaré Cristina Mendonça de Lima}

Graduada em Ciências Contábeis pela Universidade Federal de Rondônia. Trabalha no Banco HSBC/PVH/RO. mendoncadelima@hotmail.com

\section{Patricia Pantoja dos Santos Correia}

Graduada em Ciências Contábeis pela Universidade Federal de Rondônia. Trabalha no Escritório de Contabilidade Alpha.alphacontabil2@hotmail.com

\section{Resumo}

Este artigo proporciona uma análise sobre gestão em Organizações do Terceiro Setor, tendo como estudo de caso a Associação Pestalozzi de Porto Velho/Ro. Essa organização é influenciada pela Pedagogia de Johann Pestalozzi, que exerceu um trabalho assistencialista focado na sociedade menos favorecida. Desta forma o objetivo geral deste estudo foi abordar a importância da gestão no terceiro setor em uma entidade que atende pessoas com necessidades educativas especiais. Constituem objetivos específicos apresentar a divisão de gestão de forma estrutural e organizacional, bem como levantar como são desenvolvidas as atividades exclusivas de aptidão individual e a inclusão desses indivíduos na sociedade e no mercado de trabalho. 0 procedimento metodológico adotado nesta pesquisa para atender aos objetivos, bem como a análise da gestão nessa Associação, iniciou-se pela pesquisa bibliográfica, de forma descritiva e pela pesquisa de campo, por meio de entrevistas semiestruturadas de forma a conhecer o processo de gestão na Associação Pestalozzi. Como resultado, o estudo aponta que a gestão do terceiro setor, na citada organização, vem sendo feita 
de forma eficiente, atingindo as metas a que se propuseram em vários segmentos da sociedade, exercendo o desenvolvimento de suas atividades com amor e dedicação para uma população de necessidade especial.

Palavras-chave: Gestão. Organização. Terceiro setor. Pestalozzi.

\title{
MANAGEMENT IN THE THIRD SECTOR ORGANIZATIONS: PESTALOZZI ASSOCIATION FOR PORTO VELHO
}

\begin{abstract}
This article provides an analysis of management in Third Sector Organizations, taking as a case study to Pestalozzi Association for Porto Velho/R0. This organization is influenced by pedagogy Johann Pestalozzi, who has had a focus on underprivileged society welfare work. Thus the aim of this study was to address the importance of management in the third sector in an organization that serves people with special needs. Noting the specific objectives of the present management division of structural and organizational form as well as to raise as they are developed the unique activities of individual fitness and the inclusion of these individuals in society and the labor market. The approach used in this research to meet the objectives as well as the analysis of management within this Association , initiated by the literature search, descriptively and by field research through semi-structured interviews in order to know the process of managing the Association Pestalozzi. As a result, the study points out that the management of the third sector, in the above-mentioned organization, is being carried out in an efficient manner, reaching the targets the proposed in various segments of society, exercising the development of its activities with love and dedication for a population of special need.
\end{abstract}

Keywords: Management. Organization. Third sector. Pestalozzi.

\section{Sumário}

1 Introdução. 2 Fundamentação Teórica. 2.1 Gestão e Organização do Terceiro Setor. 2.2. Características das Organizações do Terceiro Setor. 2.3 Organização do Terceiro Setor: Pestalozzi. 2.3.1 Associação Pestalozzi de Porto Velho. 3 Procedimentos Metodológicos. 4. Resultado e Discussões. 4.1 A Organização Didático-Pedagógica. 4.2 Análise dos Resultados. 5 Considerações Finais. 6 Referências. 


\section{INTRODUÇÃO}

Este texto tem como propósito o conhecimento da Gestão em Organizações do Terceiro Setor, trazendo como esboço principal a Associação Pestalozzi de Porto Velho/RO, que apresenta todas as características de uma entidade sem fins lucrativos, visando à qualidade de vida para o desenvolvimento econômico e instituição de projetos, suprindo necessidades sociais básicas.

A realidade capitalista é composta de várias diferenças sociais que prejudicam a sociedade como um todo, demandando para uma visão ampla e consistente do problema social. Diante das circunstâncias, foi constituído um novo segmento para suprir as falhas do Estado, o Terceiro Setor, com a finalidade de atender à demanda social ocasionada pelo capitalismo, e "renovação do espaço público, o resgate da solidariedade e da cidadania, a humanização do capitalismo e, na medida do possível, a superação da pobreza” (Falconer, 1999, p. 9).

O objetivo deste trabalho foi verificar como é executada a gestão em uma entidade do Terceiro Setor. Fundamenta-se no seguinte questionamento: A Associação Pestalozzi de Porto Velho/RO, em sua gestão administrativa, atende aos princípios sociais propostos em seu estatuto?

No ensaio, o objetivo geral foi abordar a importância da gestão no Terceiro Setor como propulsor de resultados positivos e seus reflexos no aumento da inclusão social em uma entidade que atende pessoas com necessidades educativas especiais. Apresenta como objetivos específicos a forma estrutural e organizacional bem como a divisão administrativa e gerenciamento para atender vários segmentos em desenvolvimento instituídos pela Associação Pestalozzi de Porto Velho. Também visa a analisar como são desenvolvidas as atividades exclusivas de aptidão individual e a inclusão desses sujeitos na sociedade e no mercado de trabalho. 
O procedimento metodológico é de caráter descritivo, bibliográfico e estudo de campo, com entrevistas semiestruturadas e visitas in loco, para ciência de sua estrutura física e gerencial, bem como da execução dos seus projetos no atendimento específico a uma clientela que necessitada de acolhimento especial, ou seja, todas as crianças e jovens cujas necessidades envolvam deficiências ou dificuldades de aprendizagem.

O trabalho foi estruturado da seguinte forma: primeiramente pelo referencial teórico com os seguintes temas: Gestão e Organização do Terceiro Setor, Características das Organizações do Terceiro Setor, Organização do Terceiro Setor: Pestalozzi, Associação Pestalozzi de Porto Velho, Organizações Didáticas e Pedagógicas, continuando com os procedimentos metodológicos, dando evidência aos resultados e discussões, expõe-se as considerações finais.

As organizações do Terceiro Setor têm como objetivo melhorar a qualidade de vida das pessoas, criando projetos e atividades sociais nas áreas de educação e saúde, essas organizações surgiram de uma nova conjuntura social em que o tamanho dos problemas impõe a necessidade de se desenvolver novas soluções distintas que sejam capazes de reduzir a exclusão social e construir uma sociedade mais justa. A maioria das associações reconhece sua grande importância, percebendo que não sobrevive só com a boa vontade de poucos, mas sim de formas de gestão voltadas para resultados, com definições de liderança, foco nas pessoas e principalmente captar recursos para o sustento da Associação. 


\section{FUNDAMENTAÇÃO TEÓRICA}

\subsection{Gestão e Organização do Terceiro Setor}

Para obtenção de resultados positivos em uma entidade, o gestor precisa usar de meios estratégicos para planejar e definir metas, criando circunstâncias motivadoras que envolvam sua equipe de trabalho para que seus objetivos sejam executados conforme o conhecimento, modelos e técnicas de sua organização.

Na percepção de Chanlat (1995, p. 119), gestão é um “conjunto de práticas administrativas colocadas em execução pela direção de uma empresa para atingir os objetivos que ela tenha fixado”. Para este autor, o modelo de gestão compreende o estabelecimento das condições e organização do trabalho, a natureza das relações hierárquicas, os tipos de estruturas organizacionais, os sistemas de avaliação, o controle dos resultados, as políticas em matéria de gestão de pessoal e os objetivos, os valores e a filosofia da gestão que o inspiram.

Todo o método de gestão, segundo Chanlat (1995) é uma construção social, que pode ser influenciado, ao mesmo tempo, pelos fatores internos e externos. Os fatores internos da organização estão ligados à estratégia perseguida, à tecnologia, às histórias, às tradições, aos recursos, ao tipo de pessoal e à personalidade dos dirigentes. Os fatores externos, por sua vez, estão relacionados ao contexto econômico, político, cultural e social no qual a organização está inserida.

De acordo com Reed (1997), na perspectiva técnica, a gestão é orientada para meios, centrados nos mecanismos estruturais neutros e racionais que objetivam o alcance de resultados coletivos preestabelecidos e inatingíveis sem sua aplicação. Assim, as estruturas organizacionais são concebidas como mecanismos formais de coordenação e controle do 
desempenho de tarefas. Os modelos de relações sociais institucionalizados são impostos, os gestores exercem uma espécie de controle limitado centrado no desenvolvimento organizacional, que se propõe ser predeterminado, independentemente da vontade e da ação humana.

As organizações públicas com gestão social servem de mecanismos de ligação das entidades públicas às entidades privadas, constituindo assim as organizações do Terceiro Setor. Numa perspectiva mais ampla, Rodrigues (1998) assevera ser o Terceiro Setor a sociedade civil que se organiza e busca soluções próprias para suas necessidades e problemas, fora da lógica do Estado e do mercado e ainda cita os cinco pré-requisitos para a caracterização de uma organização do Terceiro Setor adotados na definição estrutural proposta por Salamon e Anheier (1996): ser organizada, isto é, ter algum grau de institucionalização; ser privada, ou seja, institucionalmente separada do governo; não existir distribuição de lucros; ser autogovernável e por fim ter algum grau de participação voluntária, mesmo que apenas no Conselho Diretor (Rodrigues, 1998).

Para Falconer (1999, p. 9), o Terceiro Setor surge da necessidade de suprir falhas do Estado - ente público - e de algumas empresas privadas:

Na década de noventa, o Terceiro Setor surge como portador de uma nova e grande promessa: a renovação do espaço público, o resgate da solidariedade e da cidadania, a humanização do capitalismo e, na medida do possível, a superação da pobreza. Uma promessa realizada através de atos simples e fórmulas antigas, como o voluntariado e filantropia, revestidas de uma roupagem mais empresarial. Promete-nos, implicitamente, um mundo onde são deixados para trás os antagonismos e conflitos entre classe e, se quisermos acreditar promete-nos muito mais. 
As ações solidárias alcançaram conquistas e espaço no sistema econômico do país, no qual veio constituir um novo segmento estruturado e organizado em amparar a sociedade nas áreas de educação, saúde, lazer e profissionalização. Assim, o Terceiro Setor fortaleceu e tornou-se fundamental no desenvolvimento socioeconômico do país.

Segundo Marçon e Escrivão Filho (2001) é preciso entender o que constitui a realidade dessas organizações, para aceitar então que o conhecimento sobre sua gestão deve ser produto social de seu cotidiano, e não algo exclusivamente originado nas práticas do mercado e do Estado.

Para Tenório (2006) e Teodósio (2001), contudo, o maior desafio do Terceiro Setor é desenvolver uma estrutura de gestão adequada às peculiaridades com as seguintes características: flexibilidade, criatividade e sensibilidade.

A constituição do Terceiro Setor, segundo Silva (2008, p. 23), é composto por entidades de interesse social, com finalidade econômica podendo prospectar superávit sem objetivar lucros, tratando-se de qualquer pessoa jurídica constituída pela iniciativa privada como entidade sem fins lucrativos. As Organizações Não Governamentais constituem-se - por meio de estatuto - como associações ou fundações, e são conhecidas como entidades do Terceiro Setor. Estas são beneficiadas por regulamentações legais específicas que lhes concedem imunidades ${ }^{1}$ e isenções tributárias ${ }^{2}$ e previdenciárias. Tais benefícios estão regulamentados pelas legislações

\footnotetext{
${ }^{1}$ Segundo Silva (2008, p. 32), imunidade é a situação tributária caracterizada quando o contribuinte fica formalmente desobrigado de recolher impostos graças a uma garantia constitucional.

${ }^{2} \mathrm{Na}$ concepção de Silva (2008, p. 34), ocorre isenção tributária quando “o contribuinte está desobrigado de recolher impostos por um período predefinido, seja, determinado ou indeterminado. Trata-se de uma situação precária que poderá ser suspensa a qualquer tempo, seja por vencimento do prazo estabelecido ou em razão de mudanças na política de captação de determinado tributo”.
} 
das três instâncias de poder: federal, estadual e municipal (Código Tributário Nacional; Legislação sobre Cofins, PIS, IPI, Imposto de Importação, Contribuição Social Sobre o Lucro, ICMS, IPVA, IPTU e ISSQN).

Na visão de Tachizawa (2012, p. 6), este setor ocupa espaços não preenchidos pelo Estado e pela atuação do setor privado, que enfatiza a comercialização de bens e serviços a fim de atender à expectativa de um mercado comercial. As alianças feitas em diversos segmentos sociais acontecem com a captação de recursos no mercado, visando à realização de atividades que não estariam sendo desenvolvidas pelo Estado. Nesse panorama, as Organizações Não Governamentais - ONGs -, vêm demonstrando em diversos setores da área social competência para elaborar e executar projetos que possibilitam ações sociais transformadoras.

Nesse contexto o Terceiro Setor é visto como iniciativa privada de utilidade pública, com atributos sociais, filantropia e inclusão no mercado de trabalho sem fins lucrativos, beneficiando a uma população desprovida e excluída da sociedade capitalista.

\subsection{Características das Organizações do Terceiro Setor}

As ações sociais instituídas pelo ente público com a cooperação das entidades privadas constituem organizações sem fins lucrativos, que se doam desempenhando atividades com didáticas peculiares para uma população de necessidades educativas especiais. ${ }^{3}$

\footnotetext{
${ }^{3}$ Necessidades educativas especiais - NEE. O conceito de NEE só foi adotado e redefinido a partir da Declaração de Salamanca (Unesco, 1994), passando a abranger todas as crianças e jovens cujas necessidades envolvam deficiências ou dificuldades de aprendizagem. Desse modo, passou a envolver tanto as crianças em desvantagem como as chamadas sobredotadas, bem como crianças de rua ou em situação de risco, que trabalham, de populações remotas ou nômades, pertencentes a minorias étnicas ou culturais, e crianças desfavorecidas ou marginais, bem como as que apresentam problemas de conduta ou de ordem emocional.
} 
Segundo Oliveira e Tandon (1994), a solidariedade e a cooperação sempre caracterizaram as relações sociais, porém essas virtudes estendem-se para a esfera pública. Fazendo contraponto às ações do governo, o Terceiro Setor ajuda a destacar a ideia de que os bens e serviços públicos resultam não apenas da atuação do Estado, como também de iniciativas particulares. De acordo com Fernandes (1997) assumem uma escala coextensiva à própria ação do Estado, rompendo-se a dicotomia entre o público e o privado, para à atenção de uma população com necessidades especiais.

O Conselho Regional de Contabilidade do Rio Grande do Sul CRCRS (2011) expõe em seu guia de orientação para o profissional da contabilidade que a característica principal das organizações do Terceiro Setor é que essas não visam ao lucro, os recursos são oriundos da própria atividade, além de doações, subvenções e financiamentos, e sua aplicação deve ocorrer integralmente na própria atividade para a qual foi instituída, de acordo com estatuto. Sua natureza jurídica é abordada nos incisos I, III, IV e V do artigo 44 do Código Civil, Lei n⿳ํㅡㄹ 10.406, de 10 de janeiro de 2002. Relaciona às pessoas jurídicas de direito privado como: 1 - as associações; 2 - as sociedades; 3 - as fundações; 4 - as organizações religiosas (Incluído pela Lei $\mathrm{n}^{\mathrm{o}} 10.825$, de 22.12.2003) e 5 - os partidos políticos (Incluído pela Lei $\mathrm{n}^{\mathrm{o}} 10.825$, de 22.12.2003).

Para Tachizawa (2012, p. 6), as ONGs são entidades de natureza privada (não públicas) sem fins lucrativos, juridicamente caracterizados como associações e fundações. Nesse tipo de organização enquadram-se, também, as Organizações da Sociedade Civil (OSCs), Organizações Sociais (OSs), Organizações da Sociedade Civil de Interesse Público (Oscips).

As pessoas jurídicas de Direito Público podem ser associações, sociedades civis e fundações, de acordo com o Código Civil, e não ter nenhuma qualificação. Outros títulos existentes são o de utilidade pública, 
que dá acesso à dedução do Imposto de Renda, ou de entidade beneficente de assistência social, que permite a isenção da cota patronal da seguridade social.

Uma Oscip, segundo a Lei no 9.790/99, deve ter, obrigatoriamente, como objeto social, em seu Estatuto de constituição, pelo menos um dos seguintes objetivos:

1 - promoção da assistência social;

2 - promoção da cultura, defesa e conservação do patrimônio histórico e artístico;

3 - promoção gratuita da educação, observando-se a forma complementar de participação das organizações de que trata esta Lei;

4 - promoção gratuita da saúde, observando-se a forma complementar de participação das organizações de que trata esta Lei;

5 - promoção da segurança alimentar e nutricional;

6 - defesa, preservação e conservação do meio ambiente e promoção do desenvolvimento sustentável;

7 - promoção do voluntariado;

8 - promoção do desenvolvimento econômico e social e combate à pobreza;

9 - experimentação, não lucrativa, de novos modelos socioprodutivos e de sistemas alternativos de produção, comércio, emprego e crédito;

10 - promoção de direitos estabelecidos, construção de novos direitos e assessoria jurídica gratuita de interesse suplementar;

11 - promoção da ética, da paz, da cidadania, dos direitos humanos, da democracia e de outros valores universais;

12 - estudos e pesquisas, desenvolvimento de tecnologias alternativas, produção e divulgação de informações e conhecimentos técnicos e científicos que digam respeito às atividades mencionadas neste artigo. 
As ONGs podem ter como foco de atuação: educação; saúde; cultura; comunidade; apoio à criança e ao adolescente; voluntariado; meio ambiente; apoio à portadores de deficiências; parcerias com o governo e outras categorias de atuação.

Diante desse contexto, a pesquisa explanará sobre uma organização do Terceiro Setor, tendo como referência Pestalozzi.

\subsection{Organização do Terceiro Setor: Pestalozzi}

Johann Heinrich Pestalozzi foi um pedagogo suíço (1746-1827) que dedicou sua vida à educação com ideias pedagógicas, sendo considerado pai da Psicologia moderna, influenciando o pensamento educacional e ajudando a quem mais precisava. De acordo com Luzuriaga (1983), Pestalozzi foi o maior educador da História, tendo exercido profunda influência na formação de grandes filósofos e educadores. Teve seu ideal de vida despertado ainda na infância. Decidido a acabar com as fontes da miséria, dedicou-se à educação de órfãos, investindo nesse projeto seus recursos e sua própria vida. Em sua luta, a questão pedagógica tornou-se essencial, seu trabalho não possuía um caráter apenas assistencialista, preocupava-se com a educação que afirmava ser imperativo a todo aquele que desejasse ser considerado mestre, investigando qual o melhor, e não apenas qual o mais eficiente método para garantir o crescimento e o desenvolvimento harmonioso do aluno. Constata-se que é perceptível a preocupação de Pestalozzi com a busca pelas melhores estratégias de ensino em todas as áreas da vida do educando. Para ele, não bastava ter bons métodos de ensino da linguagem ou da matemática, era necessário investir tempo em pesquisa e avaliação dos melhores meios para ensinar o ser humano a se tornar verdadeiramente humano.

\subsubsection{Associação Pestalozzi de Porto Velho}

Diante de uma sociedade com necessidades educativas especiais no município de Porto Velho, foi criada a Associação Pestalozzi, constituída em Assembleia Geral Extraordinária, com a missão de desenvolver o 
potencial da pessoa por meio de ações educacionais, sociais e de saúde, contribuindo para o exercício da cidadania. Composta por profissionais qualificados no tratamento, a educação e ajustamento social de crianças, adolescentes e adultos, que por seu desenvolvimento mental, deficiência física, aptidões ou caráter excepcional, necessitam de assistência individual no campo médico-psicopedagógico especializado.

De acordo com Estatuto da Associação Pestalozzi de Porto Velho, de 9 de dezembro de 2003:

Em seu artigo $1^{\circ}$ - A Associação Pestalozzi de Porto Velho, foi fundada em 12/5/1978, com sede e foro em Porto Velho, Estado de Rondônia, na Rua Libero Badaró, n⿳0 3.429, bairro Costa e Silva, sem limite de duração, com personalidade jurídica distinta das de seus sócios, tem por fins o estudo, a assistência, o tratamento e a educação de crianças, adolescentes e adultos que necessitam de assistência psicopedagógica, médica, odontológica e de reabilitação.

$\S 1^{\circ}$ - A Associação não terá fins econômicos e não distribuirá resultados, dividendos, bonificações, participações ou parcela de seu patrimônio, sob nenhuma forma ou pretexto.

Conforme $\mathrm{o}$ artigo $2^{\circ}$ do estatuto, para atingir as suas finalidades a Associação poderá firmar convênios e acordos com pessoas jurídicas de Direito Privado ou de Direito Público, recorrendo ainda ao preestabelecido no artigo $5^{\circ}$ - A Associação, além de outras atividades, tem por finalidades todas as ações relacionadas com o ensino geral e funcionamento de escolas que ministram Educação Infantil, Ensino Fundamental, Médio, Superior e Pós-Graduação em todo território nacional, destinadas a oferecer oportunidade de instrução a todos, inclusive proporcionar educação a estudantes carentes de recursos, que demonstrem aptidão, e dentro das possibilidades da Instituição. 
Para a manutenção de suas atividades a Associação Pestalozzi de Porto Velho observa no artigo $7^{0}$ do Estatuto: "poderá receber recursos, doações ou contribuições voluntárias, feitas por terceiros, pelos seus responsáveis, contribuintes ou pelos próprios beneficiários dos serviços, desde que seja garantido o livre acesso aos seus serviços, a todos que deles necessitarem, independentemente de contribuições ou doação”.

\section{PROCEDIMENTOS METODOLÓGICOS}

A metodologia utilizada neste trabalho foi classificada com as seguintes características: quanto ao fim de forma descritiva, com levantamentos bibliográficos e estudo de campo.

De caráter descritivo, por narrar as ideias principais para atender ao objetivo da pesquisa. Segundo Gil (2007), a pesquisa é descritiva quando por seu "objetivo primordial ser a descrição das características de certa população ou fenômeno ou estabelecer relações entre variáveis”.

Como levantamento bibliográfico, "é desenvolvida a partir de material já elaborado, constituído principalmente de livros e artigos científicos" (Gil, 2007). A pesquisa fundamentou-se nos materiais bibliográficos dos seguintes temas e autores: Gestão e organização do Terceiro Setor, na contribuição de Chanlat (1995), Reed (1997), Rodrigues (1998), Salamon e Anheier (1996), Falconer (1999), Marçon e Escrivão Filho (2001), Tenório (2006), Teodósio (2001), Silva (2008) e Tachizawa (2012); Características das Organizações do Terceiro Setor, na participação dos seguintes autores: Fernandes (1997), Oliveira e Tandon (1994) e Tachizawa (2012); explicitando como são constituídas e geridas as Organizações do Terceiro Setor e de como as influências educacionais de Johann Pestalozzi descritas por Luzuriaga (1983) contribuíram para a constituição de entidades com a pretensão de auxiliar aos menos favorecidos do sistema capitalista no qual estamos inseridos. 
Quanto ao procedimento de estudo de campo, os dados levantados foram na Associação Pestalozzi de Porto Velho, utilizando como instrumento de coleta de dados entrevista presencial com questionário semiestruturado.

Para Gil (2007), os estudos de campo procuram muito mais o aprofundamento das questões propostas do que distribuição das características da população segundo determinadas variáveis. Esta foi composta de visitas e entrevistas com representantes da coordenação pedagógicas e administrativa sobre sua gestão, estrutura, programas e projetos executados na comunidade.

Objetivo da pesquisa é apresentar a gestão da Associação Pestalozzi de Porto Velho por meio de pesquisa bibliográfica, descritiva e estudo de campo, observando o resultado atingido com seus projetos e influências pedagógicas como estimulador social voltado à população com necessidades especiais educativas, proporcionando, assim, educação inclusiva, habilitação e realização profissional, integração e participação na comunidade como resultado de solidariedade e filantropia.

\section{RESULTADO E DISCUSSÕES}

A Associação Pestalozzi de Porto Velho, de acordo com seu Estatuto, é uma instituição não governamental, de abrangência nacional e sem fins lucrativos que visa sempre à inclusão na comunidade em todos os setores. Atualmente seus serviços estão organizados em 4 (quatro) segmentos: Unidade de Saúde; Unidade Escolar; Unidade de Profissionalização e Centro de Capacitação de Recursos Humanos. Tem como missão desenvolver o potencial da pessoa por meio de ações educacionais, sociais e de saúde, contribuindo para o exercício da cidadania.

A estrutura de funcionamento está sistematizada em conformidade com o organograma apresentado na Figura 1. 
Figura 1 - Organograma Coordenação Geral

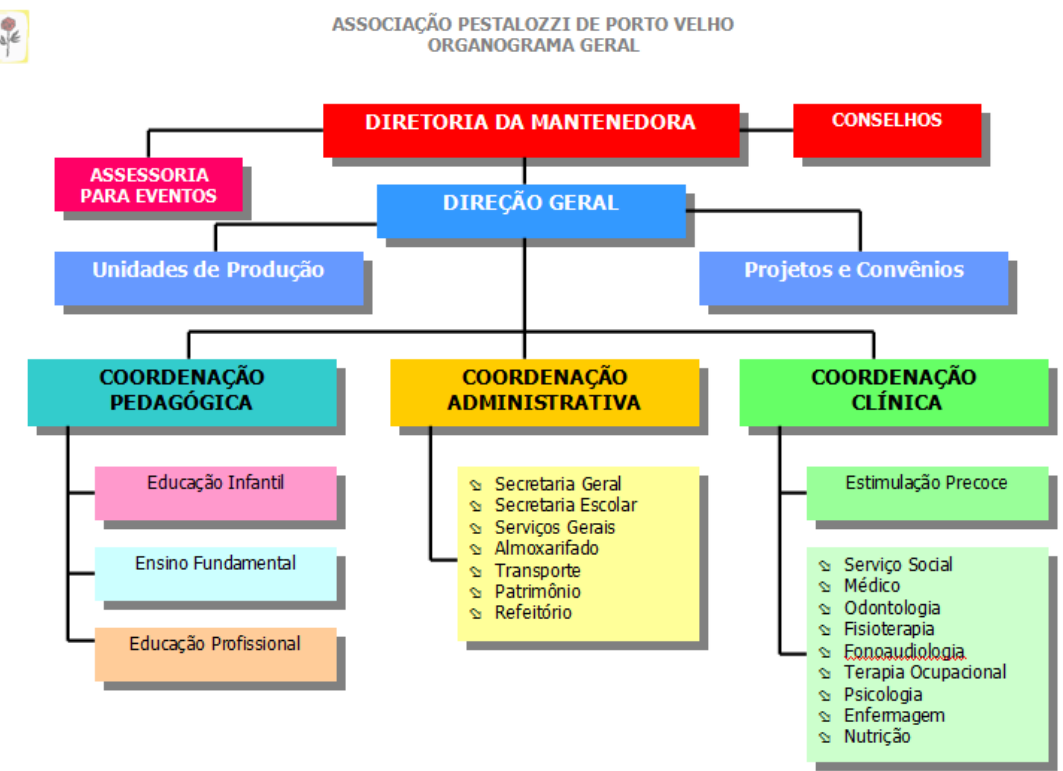

Fonte: Organograma da Associação Pestalozzi de Porto Velho/RO (2012), adaptada pelas autoras.

A Figura 1 apresenta o organograma Administrativo Geral da Associação Pestalozzi de Porto Velho/RO, composto por três coordenações: Pedagógica, Administrativa e Clínica. O estudo proposto foi sobre a gestão na coordenação pedagógica.

\subsection{A Organização Didático-Pedagógica}

Na escola Antônio Cezar de Abreu Teixeira, crianças, jovens e adultos têm acesso à escolaridade na Educação Infantil, Ensino Fundamental e na Educação de Jovens e Adultos, com propostas pedagógicas voltadas para os parâmetros curriculares nacionais e outras direcionadas para ações inclusivas. De acordo com o livro de atas, a escola foi criada em 12 
de maio de 1978, ata sob n⿳⺈ 4/78, com sede no município de Porto Velho, à rua Líbero Badaró, $\mathrm{n}^{0}$ 3.429, bairro Costa e Silva. A escola é mantida pela Associação Pestalozzi de Porto Velho, CNPJ 04.079.737/001-00, registro no CNAS nº 28010.002529/94-76 (Relatório..., 2013).

No Relatório Institucional da Pestalozzi de Porto Velho (2013), a escola tem como finalidade proporcionar a todos os alunos educação inclusiva, possibilitando sua integração e participação na comunidade e oferecer ao corpo discente condições de integrar os mecanismos de desenvolvimento para alcançar condutas compatíveis com suas idades, norteando a educação dentro dos princípios dos direitos universais do homem, garantindo à comunidade de Porto Velho e região atendimento especializado, preparando o indivíduo para o exercício da cidadania. Esse mecanismo pode ser visualizado no Quadro 1.

Quadro 1 - Estrutura Organizacional Didática e Pedagógica da Pestalozzi

\begin{tabular}{|c|l|l|}
\hline $\begin{array}{c}\text { Divisão } \\
\text { organizacional }\end{array}$ & \multicolumn{1}{|c|}{ Público-alvo } & \multicolumn{1}{c|}{$\begin{array}{c}\text { Do atendimento (2010 a } \\
\text { jun/2013) }\end{array}$} \\
\hline $\begin{array}{c}\text { Estimulação } \\
\text { Precoce }\end{array}$ & $\begin{array}{l}\text { Crianças na faixa etária } \\
\text { de 0 a 3 anos e 11 meses } \\
\text { que apresentam atraso } \\
\text { no desenvolvimento } \\
\text { neuropsicomotor, síndromes, } \\
\text { paralisia cerebral e casos de } \\
\text { alto risco. }\end{array}$ & $\begin{array}{l}\text { Este público-alvo não esta } \\
\text { sendo mais atendido desde } \\
\text { 2012, pelo fato de o MEC ter } \\
\text { exigido a distribuição por } \\
\text { município. }\end{array}$ \\
\hline $\begin{array}{c}\text { Ensino } \\
\text { Fundamental }\end{array}$ & $\begin{array}{l}\text { Alunos na faixa etária de 6 a } \\
14 \text { anos. }\end{array}$ & $\begin{array}{l}\text { A educação inicia-se pelo } \\
\text { Ensino Fundamental nesta faixa } \\
\text { de idade. }\end{array}$ \\
\hline $\begin{array}{c}\text { Programa } \\
\text { Fundamental Não } \\
\text { Seriado }\end{array}$ & $\begin{array}{l}\text { Alunos sem condições } \\
\text { de desenvolverem um } \\
\text { programa de escolaridade } \\
\text { formal, mediante adaptações } \\
\text { organizativas do currículo } \\
\text { escolar. }\end{array}$ & $\begin{array}{l}\text { Esta clientela continua } \\
\text { recebendo atendimento clínico, } \\
\text { mesmo sem desenvolver um } \\
\text { aprendizado pedagógico. }\end{array}$ \\
\hline
\end{tabular}




\begin{tabular}{|c|l|l|}
\hline $\begin{array}{c}\text { Programa } \\
\text { Fundamental } \\
\text { Seriado }\end{array}$ & $\begin{array}{l}\text { Alunos, por meio da } \\
\text { escolaridade formal, } \\
\text { (metodologia, ambiente } \\
\text { físico, materiais e recursos } \\
\text { humanos especializados), de } \\
\text { acordo com cada necessidade } \\
\text { individual. }\end{array}$ & $\begin{array}{l}\text { Alunos ativos de acordo com a } \\
\text { sua necessidade. }\end{array}$ \\
\hline $\begin{array}{c}\text { Educação para o } \\
\text { Trabalho }\end{array}$ & $\begin{array}{l}\text { Alunos acima de 14 anos, } \\
\text { inseridos ou não no } \\
\text { segmento de Educação } \\
\text { de Jovens e Adultos. Os } \\
\text { segmentos e grupos serão } \\
\text { organizados de acordo com } \\
\text { a idade cronológica, nível de } \\
\text { desempenho e conveniências } \\
\text { psicopedagógicas. }\end{array}$ & $\begin{array}{l}\text { Este público continua ativo, } \\
\text { sendo preparado para ter } \\
\text { acesso à educação profissional } \\
\text { e adaptado ao trabalho futuro. }\end{array}$ \\
\hline $\begin{array}{c}\text { Atendimento } \\
\text { Educacional } \\
\text { Especializado }\end{array}$ & $\begin{array}{l}\text { Educação profissional e } \\
\text { trabalho, Educação de } \\
\text { Jovens e Adultos e atividades } \\
\text { complementares de forma } \\
\text { integrada aos educandos de } \\
\text { 6 a 14 anos, da Instituição ou } \\
\text { não, visando à formação plena } \\
\text { para o mundo do trabalho } \\
\text { competitivo aberto, apoiado e/ } \\
\text { ou trabalho autônomo. }\end{array}$ & $\begin{array}{l}\text { Atendimentos de ensino } \\
\text { especial educativo, sendo } \\
\text { capacitados em atividades } \\
\text { aptidão individual de cada um. }\end{array}$ \\
\hline
\end{tabular}

Fonte: Relatório Institucional da Associação Pestalozzi de Porto Velho/ RO (2013), adaptado pelas autoras.

Comprometidos no aprendizado de jovens e adultos com dificuldades educacionais, a Associação possui um quadro curricular bem amplo para que sejam alcançados os propósitos de cada individuo. Diferentes dos demais, eles precisam da disponibilidade de ensino e são capazes de aprender com o auxílio de paciência e amor.

A escola fundamenta-se na Política Nacional de Educação Especial na perspectiva da Educação Inclusiva, que estabelece uma nova concepção especial que passa a complementar ou suplementar o ensino comum. $\mathrm{O}$ Atendimento Educacional Especializado - AEE - tem como atribuição identificar, elaborar e organizar recursos pedagógicos e de acessibilidade 
que eliminem as barreiras para a plena participação dos educandos, considerando suas necessidades especificas. $\mathrm{O}$ caráter pedagógico desse atendimento tem como objetivo sanar a necessidade do educando, assegurando o direito de acesso a recursos que possam potencializar suas capacidades, promovendo o seu desenvolvimento, garantindo assim uma plena convivência social e permanência na rede pública. O AEE da escola recebe pessoas com deficiência intelectual e/ou dificuldades de aprendizagem encaminhadas pela Rede pública de ensino.

A Associação está em plena atividade pedagógica e social, sua estrutura física e funcional está organizada em três divisões: a) administrativa, compreendendo a direção, conselhos, assessoria de eventos, unidade de produção e projetos e convênios; b) coordenação pedagógica, abrangendo: artes cênicas, informática e esporte, Ensino Profissional, Fundamental e Educação Infantil; c) coordenação administrativa; para atender ao objetivo geral da Associação - qualidade de vida para pessoas com necessidades especiais - está organizada pela divisão curricular apresentada no organograma da Figura 2.

Figura 2 - Organograma de estrutura de funcionamento

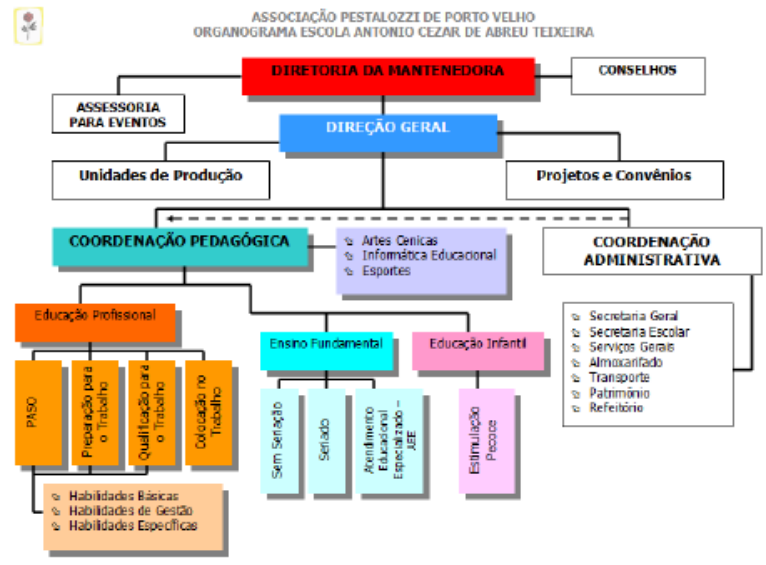

Fonte: Organograma da Associação Pestalozzi de Porto Velho/RO (2012), adaptado pelas autoras. 
A estrutura organizacional e administrativa apresentada no organograma da Figura 2 gira em torno ao ambiente pedagógico das três fases de ensino da Associação (Educação Infantil, Ensino Fundamental e Profissional).

$1^{\underline{a}}$ Fase - Estimulação Precoce: Consiste na repetição de diferentes exercícios sensoriais, ampliando os aspectos emocionais proporcionando às crianças sensação de segurança e prazer, estimulando as habilidades cognitivas por meio do lúdico para facilitar a aprendizagem, explorando o desenvolvimento de atividades pertinentes ao exercício da curiosidade e da imaginação. São trabalhadas as áreas: cognitiva, motora, linguagem, socioemocional e autocuidados, estimulando os movimentos voluntários, mudanças de posição e postura, coordenação motora fina e global, apropriação da imagem corporal, esquema corporal, linguagem expressiva e compreensiva, movimentos orofaciais, noção espaçotemporal, percepções tátil, auditiva, visual, gustativa e olfativa, favorecendo o desenvolvimento desses aspectos e propiciando a socialização e interação global de forma lúdica, respeitando o nível de desenvolvimento e a idade de cada criança.

$2^{a}$ Fase - Ensino Fundamental dividido em dois segmentos:

Não seriado: constituído dos grupos 1 e 2, para alunos sem condições de desenvolverem um programa de escolaridade formal, com quadro curricular específico, sem prazo para alcançar desempenho previsto. A proposta pedagógica tem como componentes curriculares: Identidade e Autonomia; Base Nacional Comum: Língua Portuguesa, Matemática, Ciências, História, Geografia, Educação Física, Artes e Educação Religiosa.

Seriado: destinado a alunos em condições de desenvolverem um programa de escolaridade formal, por meio de metodologia, ambiente físico, materiais e recursos humanos especializados. O quadro curricular terá ordenação especial, com a $1^{\mathrm{a}}$ série sendo oferecida em três fases e as séries seguintes conforme o modelo do ensino regular, diferenciado quanto à flexibilidade de tempo, não havendo exigência de um ano letivo 
para o cumprimento dos conteúdos propostos. Os componentes curriculares do trabalho pedagógico são: Base Nacional Comum: Língua Portuguesa, Matemática, Ciências, História, Geografia, Educação Física, Artes e Educação Religiosa.

$3^{\underline{a}}$ Fase - Educação Profissional - subdividida em quatro programas:

Programa 1 - Preparação para o Trabalho - compõe-se de avaliação para o trabalho e pré-profissionalização, oferecendo vivências em atividades práticas que revelarão as potencialidades, aptidões e interesses do aprendiz.

Programa 2 - Qualificação para o Trabalho - compõe-se de treinamento profissional, para desenvolver com atividades práticas o potencial do aprendiz, executando e produzindo o trabalho com qualidade e responsabilidade. Habilitação profissional que propicia ao aprendiz, em nível mais formal e sistematizado, a aquisição e/ou desenvolvimento de conhecimentos e habilidades associados a uma profissão.

Programa 3 - Colocação no Mercado de Trabalho - compõe-se de: Emprego Competitivo, Emprego Apoiado, Trabalho Autônomo.

\section{Programa 4 - Programa de Atividade Socioeducacional (PASO)}

Compõe-se de atividades que oportunizam o desenvolvimento das habilidades de gestão e habilidades específicas voltada para a inclusão no trabalho familiar. Neste serão utilizadas todas as adaptações curriculares necessárias ao desenvolvimento do aluno, oferecendo atendimento educacional especializado, proporcionando um ensino diferenciado e estruturado em ambientes pedagógicos e clínicos, em que de forma compactada procura favorecer e possibilitar a aprendizagem acadêmica e de serviço de acompanhamento institucional.

Aliado à aprendizagem do PASO, há o Programa Acadêmico voltado ao desempenho de Habilidades Básicas da Educação Profissional para alunos acima de 14 anos que não tiveram acesso ou continuidade 
de estudo no Ensino Fundamental na idade própria. Nesse programa os alunos aprendem o exercício de funções em que demonstram facilidade: auxiliar de sala, auxiliar de jardinagem, auxiliar de horticultura, auxiliar de cozinha e auxiliar de serviços gerais.

O Quadro 2 apresenta detalhadamente como a Associação Pestalozzi está organizada em seus ambientes pedagógicos e no atendimento clínico, revelando a intensa preparação para oportunizar a educação e os cuidados médicos, respeitando os desenvolvimentos de atividades de inteligência, coordenação motora e raciocínio lógico, para então atingir os objetivos estabelecidos em sua fundação, como as expectativas da sociedade.

Quadro 2-Ambiente pedagógico e clínico proporcionado aos clientes do PASO

\begin{tabular}{|c|l|}
\hline \multicolumn{2}{|c|}{ Ambiente Pedagógico } \\
\hline $\begin{array}{c}\text { Ambiente } \\
\text { Produçãão Textual e }\end{array}$ & $\begin{array}{l}\text { Este ambiente oportunizará ao educando estimular o } \\
\text { uso funcional da linguagem oral e escrita, trabalhando } \\
\text { aspectos pedagógicos da linguagem, da escrita de textos } \\
\text { com sequência lógica e reprodução de textos e histórias } \\
\text { de maneira crítica, favorecendo o processo de ensino e } \\
\text { aprendizagem que contribui para a formação integral do } \\
\text { aluno. }\end{array}$ \\
\hline $\begin{array}{c}\text { Ambiente de } \\
\text { Ciências Sociais e } \\
\text { Naturais }\end{array}$ & $\begin{array}{l}\text { Espaço destinado à vivência e discussão acerca do } \\
\text { exercício da cidadania, a relação do homem-sociedade e } \\
\text { meio ambiente, buscando informações sobre sua origem, } \\
\text { família, compreensão do mundo e suas transformações, } \\
\text { situando-se como indivíduo participativo e parte integral } \\
\text { do universo. }\end{array}$ \\
\hline $\begin{array}{c}\text { Ambiente de } \\
\text { Raciocínio Lógico }\end{array}$ & $\begin{array}{l}\text { Neste ambiente o educando será orientado a procurar } \\
\text { a solução de um problema, explorar as possibilidades, } \\
\text { levantar hipóteses, fazer experimentos, chegando a uma } \\
\text { conclusão, podendo ser lógico ou não. }\end{array}$ \\
\hline Ambiente de & $\begin{array}{l}\text { Espaço de vivência e utilização dos recursos } \\
\text { tecnológicos e inclusão digital, favorecendo o } \\
\text { Informática } \\
\text { exercício da coordenação motora, raciocínio lógico e o } \\
\text { desenvolvimento da inteligência. }\end{array}$ \\
\hline
\end{tabular}




\begin{tabular}{|c|l|}
\hline \multicolumn{2}{|c|}{ Ambientes Clínicos } \\
\hline $\begin{array}{c}\text { Ambiente Clínico } \\
\text { de Fonoaudiologia }\end{array}$ & $\begin{array}{l}\text { Momento destinado à intervenção fonoaudiológica nos } \\
\text { distúrbios da oralidade e da escrita, importante para } \\
\text { reduzir as dificuldades encontradas na aprendizagem. }\end{array}$ \\
\hline $\begin{array}{c}\text { Ambiente Clínico } \\
\text { de Psicologia }\end{array}$ & $\begin{array}{l}\text { Momento destinado a atendimentos psicológicos nos } \\
\text { distúrbios da aprendizagem reduzindo as barreiras } \\
\text { encontradas pelo aluno. }\end{array}$ \\
\hline \multicolumn{2}{|c|}{ Centro de Capacitação de Recursos Humanos } \\
\hline $\begin{array}{l}\text { Um espaço permanente e sistematizado de estudos, pesquisas e troca } \\
\text { de experiências entre pessoas de diferentes áreas de conhecimento, na } \\
\text { perspectiva de transformação social, por uma sociedade mais justa, igualitária } \\
\text { e solidária. É aberta a toda comunidade e as atividades são em forma de } \\
\text { cursos, palestras, sessões de estudos, estágios supervisionados, entre outros. }\end{array}$ \\
\hline \multicolumn{2}{|c|}{ Atividade Complementar } \\
\hline Artes Cênicas & $\begin{array}{l}\text { Busca despertar o gosto pelas artes cênicas, por meio da } \\
\text { criação e adaptação de mímicas e movimentos corporais, } \\
\text { para transmitir histórias, ideias, sentimentos e emoções, } \\
\text { estimulando sensibilidade artística, imaginação, } \\
\text { capacidade de concentração, controle emocional, } \\
\text { iniciativa, persistência, flexibilidade e curiosidade, } \\
\text { contribuindo para sua autoestima e formação de um } \\
\text { cidadão melhor. }\end{array}$ \\
\hline $\begin{array}{c}\text { Esportes: } \\
\text { atletismo e bocha) }\end{array}$ & $\begin{array}{l}\text { O ambiente permite aos alunos o estímulo motor, } \\
\text { a integração e o uso de jogos didáticos, quando } \\
\text { desenvolvem projetos que procuram ressaltar a } \\
\text { solidariedade e a articulação de agentes sociais dos } \\
\text { educandos. }\end{array}$ \\
\hline $\begin{array}{l}\text { Inforividades ricas em movimentos, trabalhando o } \\
\text { indivíduo de forma completa, preparando-o fisicamente } \\
\text { e psicologicamente, respeitando seus limites e } \\
\text { conscientizando-o de sua capacidade. Estimula a } \\
\text { disciplina, a cooperação e o respeito mútuos, visa a } \\
\text { melhorar o seu comportamento e o seu caráter, refletindo } \\
\text { no aumento de sua autoestima para a formação de um } \\
\text { indivíduo mais digno e consequentemente mais feliz. }\end{array}$ \\
\hline
\end{tabular}

Fonte: Relatório institucional da Associação Pestalozzi de Porto Velho/ RO (2013), adaptado pelas autoras. 
O Quadro 2 mostra o ambiente pedagógico e clínico proporcionado aos clientes do Programa - PASO, o qual visa a melhorar o desempenho e habilidades, objetivando aos participantes do mesmo a independência nos afazeres básicos (cuidar de sua higiene pessoal, trabalhos domésticos) e ainda habilidades profissionais.

\subsection{Análise dos Resultados}

A pesquisa foi instigada a levantar dados conceituais sobre gestão em organizações do Terceiro Setor a partir de publicações dos autores descritos no referencial bibliográfico dessa pesquisa.

Com o agrupamento das informações, foi constatado e observado que os conceitos sobre gestão fazem parte da rotina pessoal e profissional. Em vista disso, buscou-se analisar uma entidade sem fins lucrativos, que desenvolve suas atividades com dedicação e amor de modo a gerir e beneficiar a sociedade menos favorecida com projetos e programas sociais amparados pela Lei do Terceiro Setor 9.790 de 23/3/99.

As organizações do Terceiro Setor enfatizam o estruturamento organizacional diante das deficiências administrativas do Estado, contribuindo para as mudanças sociais. Inclui-se como Terceiro Setor por não se agregar a valores econômicos nem obtenção de lucros. Para tanto, foi escolhida a Associação Pestalozzi de Porto Velho, com a finalidade de inclusão e aprimoramento de habilidades profissionais para crianças, jovens e adultos com necessidades educativas especiais. Observou-se ainda a não limitação de permanência educacional, os educandos são distribuídos de acordo com o Quadro 1, percorrendo todas as fases curriculares até apresentarem afinidades específicas do Programa Acadêmico.

O Programa de Atividade Socioeducacional - PASO disponibiliza atividades que estimulam habilidades para inclusão fora do ambiente escolar para aqueles que almejam a independência, familiar ou não, mas que estão 
dispostos a descobrir o mundo sozinhos (aprendem a lavar louça, escovar os dentes, pentear o cabelo, fazer uma refeição, limpar a casa, andar de ônibus, andar na rua, dentre outros.)

O quadro administrativo da Associação dispõe de profissionais educadores cedidos pelo governo, fazem treinamentos direcionados à educação inclusiva, elaboram projetos para obter recursos e investem na melhoria do seu espaço físico.

De acordo com os dados coletados e analisados pode-se afirmar que a Associação Pestalozzi de Porto Velho é uma organização do Terceiro Setor que busca melhorar a qualidade de vida da comunidade, atendo pessoas com necessidades educativas especiais por meio da sua gestão, estando frente a frente com os problemas sociais, suprindo as necessidades da Associação por meio de projetos sociais, e com a colaboração de pessoas - que se doam com trabalho físico e auxílio financeiro - e entidades privadas na doação de bens móveis que são vendidos a preços baixos para arrecadar fundos que irão atender pequenas despesas da Associação.

\section{CONSIDERAÇÕES FINAIS}

O trabalho mostrou a gestão de uma organização do Terceiro Setor, permitindo-nos constatar a importância de um adequado planejamento estratégico como o foco principal da instituição, tendo como princípio a dedicação dos envolvidos nos projetos, nos quais eles são capacitados e treinados para lidar com o problema social atendendo às necessidades específicas, proporcionando melhor desempenho pessoal e profissional.

A gestão não é tão simples quanto parece, existe todo um procedimento de estudo, estrutura local, treinamentos, capacitação, organização e foco na necessidade a ser atendida. A gestão de uma entidade para atendimento de pessoas especiais para ser eficiente tem de, além de ser 
aprovado nas secretarias e estar de acordo com as normas legislativas, dispor de pessoas trabalhando com muita prudência, dedicação, compreensão e amor.

Com essa pesquisa, tivemos uma visão do problema proposto, identificamos que é possível obter resultados positivos fazendo uma junção entre o Estado como ente público, entidades privadas e a sociedade civil participante, focadas no trabalho social, capacitação de jovens para o mercado profissional, sistema educacional, espaço para o lazer, reinclusão de apenados e dependentes químicos e melhoria na saúde como condição para uma boa qualidade de vida.

No período levantado no estudo - 2010 a jun/2013 - e de acordo com os dados apresentados, pode-se concluir que a Associação Pestalozzi de Porto Velho/RO dispõe de uma eficiente estrutura gerencial, com atividades pedagógicas para estímulo das habilidades individuais, contribuindo para a formação do homem com qualidade e comodidade.

A Associação Pestalozzi de Porto Velho/RO foi Influenciada pela doutrina de Johann Pestalozzi, que dedicou sua vida aos menos favorecidos. Essa doutrina espalhou-se pelas nações e entidades interessadas em dar continuidade à formação e criação das crianças, preparando-as para o futuro com qualidade de ensino, profissionalização e empenho na construção de uma nova sociedade estruturada e organizada, atingindo os padrões de cidadania e humanismo. Nessa associação resgata-se a atenção para o maior benefício de inclusão social de crianças, jovens e adultos mal-formados na gestação devido a alguns fatores genéticos que venham a causar dificuldades ou nítidos atrasos em seu desenvolvimento neuropsicomotor, aquisição da fala e outras habilidades.

Conclui-se que a educação inclusiva proporciona o melhor atendimento às pessoas portadoras de necessidades especiais e a Associação Pestalozzi de Porto Velho/RO tem atingido as expectativas dos familiares e da coletividade. Não se pode esquecer que o ser humano possui inú- 
meras características que os diferem uns dos outros e é possível ajudar sendo e buscando parceiros com o intuito único e essencial de promover a solidariedade, o respeito e a qualidade na vida de todos que necessitam de atendimento especializado por profissionais, usando nossos corações para abrigar os menos favorecidos desse sistema capitalista intransigente.

\section{REFERÊNCIAS}

ASSOCIAÇÃO PESTALOZZI DE PORTO VELHO - RO. Relatório Institucional. 2013. Disponível em: <www.pestalozzipvh.com.br/institucional. php $>\square$. Acesso em: 20 jul. 2013.

CHANLAT, Jean-François. Modos de gestão, saúde e segurança no trabalho. In: DAVEL, E; VASCONCELOS, J. Recursos humanos e subjetividade. Petrópolis: Vozes, 1995.

CONSELHO REGIONAL DE CONTABILIDADE DO RIO GRANDE DO SUL. Terceiro setor: guia de orientação para o profissional da contabilidade. Uma publicação do CRCRS - Conselho Regional de Contabilidade do Rio Grande do Sul. Porto Alegre - RS. Dez, 2011.

FALCONER, A. P. A promessa do terceiro setor: um estudo sobre a construção do papel das organizações sem fins lucrativos e do seu campo de gestão. 1999. Dissertação (Mestrado) - USP, São Paulo, 1999.

FERNANDES, Rubens César. O que é o terceiro setor. In: IOSCHPE, Evelyn et al. $3^{\circ}$ Setor: desenvolvimento social sustentado. Rio de Janeiro: Paz e Terra, 1997.

GIL, Antônio Carlos. Métodos e técnicas de pesquisa social. 5. ed. São Paulo: Atlas, 2007.

LUZURIAGA, Lorenzo. História da educação e da pedagogia. São Paulo, Editora Nacional, 1983. 
MARÇON, Denise; ESCRIVÃO FILHO, Edmundo. Gestão das organizações do terceiro setor: um repensar sobre as teorias organizacionais. In: ENCONTRO NACIONAL DOS PROGRAMAS DE PÓS-GRADUAÇÃO EM ADMINISTRAÇÃO, 25., 2001, Foz do Iguaçu. Anais... Campinas: Anpad, 2001.

OLIVEIRA, Miguel Darcy; TANDON, Rajesh. A emergência de uma sociedade civil global. In: OLIVEIRA, Miguel Darcy; TANDON, Rajesh. Cidadãos: construindo a sociedade civil planetária. Civicus: Aliança Mundial Para a Participação dos Cidadãos, 1994.

REED, M. Sociologia da gestão. Oeiras: Celta, 1997.

RODRIGUES, Maria Cecília Prates. Demandas sociais vs crise de financiamento: o papel do terceiro setor no Brasil (versão preliminar). Texto para discussão - CEEG, n. 11, Rio de Janeiro: FGV; Ibre, out. 1998.

SALAMON, Lester; ANHEIER, Helmut. The emerging sector: an overview. Manchester: Manchester University Press, 1996.

SILVA, Maria das Graças Bigal Barboza da; SILVA, Ana Maria Viegas da. Terceiro setor: gestão das entidades sociais: (ONG - Oscip- Os). Belo Horizonte: Fórum, 2008.

TACHIZAWA, Takeshy. Organizações não governamentais e terceiro setor. criação de ONGs e estratégias de atuação. 5. ed. São Paulo: Atlas, 2012.

TENÓRIO, F. (Org.). Gestão de ONGs: principais funções gerenciais. Rio de Janeiro: Editora da Fundação Getúlio Vargas, 2006.

TEODÓSIO, Armindo S. S. Pensar o terceiro setor pelo avesso: dilemas e perspectivas da ação social organizada na gestão pública. In: ENCONTRO DA ASSOCIAÇÃO NACIONAL DE PÓS-GRADUAÇÃO E PESQUISA EM ADMINISTRAÇÃO - ENANPAD, 25. 2001, Campinas. Anais... Rio de Janeiro: Anpad, 2001. 1 CD-ROM.

Recebido em: 6/5/2014

Aceito em: 11/8/2014 